\title{
Factors Influencing the Choice of Place of Delivery among Women in Rural Northern Ghana: A Cross-sectional Descriptive Study
}

\author{
Agulu Gilbert Gangtaba \\ Regional Health Directorate PMB, Bolgatanga, \\ Ghana Health Services, Ghana \\ Mitsuaki Matsui (Supervisor/ Associate Professor) \\ Yasuhiko Kamiya (Co-Supervisor/ Professor)
}

School of Tropical Medicine and Global Health, Nagasaki University, Japan

Doi:10.19044/esj.2021.v17n7p272

Submitted: 02 June 2020

Accepted: 27 February 2021

Published: 28 February 2021
Copyright 2021 Author(s)

Under Creative Commons BY-NC-ND

4.0 OPEN ACCESS

Cite As:

Gangtaba G. A., Matsui M. \& Kamiya Y. (2021). Factors Influencing the Choice of Place of Delivery among Women in Rural Northern Ghana: A Cross-sectional Descriptive Study. European Scientific Journal, ESJ, 17(7), 272. https://doi.org/10.19044/esj.2021.v17n7p272

\section{Abstract}

Background of the Study: Studies have shown that three-quarters of all maternal deaths happen during childbirth and the immediate postpartum periods. Most of these deaths occur due to a lack of support from a health care provider. Globally, in 2016, one out of five childbirths took place without the assistance of a skilled birth attendant (SBA). The coverage among women in deprived areas is even lower. Women's choice of a birthing place is often influenced by a complex mixture of factors ranging from individual, household, accessibility, health facility and provider-related factors, socioeconomic status, etc. Despite many interventions put in place in Ghana to encourage the use of health facilities for deliveries, utilization remains inadequate and the reasons have not been explored in detail. This study examines the factors affecting utilization of health facilities for delivery by pregnant women in the West Mamprusi Municipality (WMM) of Northern Ghana by adopting the three delays model. Materials and Methods: A crosssectional household survey of 381 women within the age group, 15-49 years, was conducted from January to March 2019 in the WMM. Data was collected using a structured questionnaire consisting of open and closed-ended 
questions. Data entry was done using IBM-SPSS version 25 statistical software, and it was exported to Stata version 15 statistical software for the analysis. Descriptive statistics and Chi-square tests were done. Bivariate and multivariate logistic regression analysis was conducted to identify the variables associated with facility delivery. All statistical tests were set at a 5\% level of significance and a 95\% confidence interval. Results: This study revealed that $75.3 \%$ of the respondents delivered their last child in a health facility while $24.7 \%$ delivered at home. The ANC coverage was high (98.2\%). However, this does not translate into the proportion of facility deliveries. Factors leading to the choice of the delivery place include; poor health care provider's attitudes, low knowledge about the signs of labor, poor quality of health services, sociocultural beliefs, low socioeconomic status of women, low educational level of mothers, and inaccessibility to health services. It was observed that respondents with a higher educational level were almost four times [AOR=3.66; 95\% CI:1.19-68.9] more likely to deliver their children in a health facility. Women who made more ANC contacts with health care providers have a higher chance [AOR=1.17; 95\% CI:1.04-36.7] of delivering in a health facility than those who made less or no contact. Conclusion: Though the findings show a high proportion of facility delivery in the study area, much can be achieved by intensifying health education on early initiation of ANC, signs of labor and delivery, as well as the importance of health facility delivery.

Keywords: ANC, Health facility delivery, IBM-SPSS, SBA, The three delays model, West Mamprusi Municipality

\section{Introduction}

Facility-based delivery service utilization is one of the most suitable and proven interventions to reduce maternal deaths. It contributes to safe delivery and minimizes both actual and potential complications that could lead to maternal death. The utilization of emergency obstetric and newborn care (EmONC), Antenatal care (ANC), Postnatal care (PNC), and skilled birth attendants (SBAs) lead to improved maternal and neonatal health and prevent mortality in developing countries (Yaya, Bishwajit, Uthman, \& Amouzou, 2018). Press (2017) posits that approximately $75 \%$ or more maternal deaths could be averted if all women have access to the interventions for preventing or treating pregnancy and birth-related complications. However, factors leading to a choice of delivery place for women in Northern Ghana are largely unstudied.

According to Rawe (2011), it is unhealthy for women to risk their lives and that of their babies by going through childbirth without expert care. Globally, 48 million women give birth in the absence of a medical 
professional, while 358,000 maternal deaths and 814,000 newborn deaths occur during childbirth. Maternal mortality across middle and low-income countries has seen a minimal reduction for the last two decades since the inception of the MDGs. The maternal mortality rate as of 2013 was 210 deaths per 100,000 live births. Developing countries account for $99 \%$ of global maternal deaths (United Nations, 2015).

It is estimated that three-quarters of all maternal deaths take place during delivery and in the immediate postpartum period (WHO, UNFPA, UNICEF, 1999). A report from Boerma and Mathers (2015) shows that inadequate or non-existent care during pregnancy and delivery was largely responsible for the annual deaths of an estimated 303,000 women in 2015.

Most causes of maternal deaths are due to direct obstetric causes such as hemorrhage, sepsis, unsafe abortion, obstructed labor, and hypertensive disorders (Cameron, Suarez, \& Cornwell, 2019). These complications occur around the time of delivery and are difficult to predict. However, it can be effectively managed and deaths can be averted through health facility delivery equipped with SBAs placed in an enabled environment (Gabrysch \& Campbell, 2009). Skilled attendants can perform deliveries either at home or at health facilities, but an efficient strategy for lower-income countries is to place them in health facilities with a reliable referral system (Campbell \& Graham, 2006).

The situation in Ghana is not different because the country was unsuccessful in achieving the MDGs 5 target of reducing maternal mortality to 190 per 100,000 live births, despite a reduction from 760 to 319 per 100,000 live births from 1990 to 2015 respectively (Ghana Statistical Service, Ghana Health Service \& ICF, 2018). Regardless of this decline in the mortality ratio, much reduction was expected to juxtapose with the several death-reducing interventions and policies the country has invested in. Some key interventions geared at improving maternal health care access was the implementation of the Community-based health planning and services (CHPS). This is a primary health care service whereby community health nurses are trained and provided with the basic essential logistics and accommodation to stay in the communities and provide door-to-door services to the community members. The goal of the CHPS concept was to reduce the traveling distance to health facilities and increase coverage to health care. Furthermore, the free maternal health care policy was implemented in Ghana in 2008 under the auspices of the National Health Insurance Scheme (NHIS) to help motivate women to deliver in health facilities. Apart from pregnant women enjoying free health services, babies were also entitled to free health care for the first three months after birth. In September 2013, the training of male midwives started as a pilot project in three Ghanaian midwifery training colleges. This was an attempt to augment the midwifery staffing strength in the country and to help bridge the 
access gap. Notwithstanding all these and other commendable strategies and policies put in place, maternal health in Ghana has seen little improvement.

Ghana observed a reduction in skilled delivery rate from 57 percent in 2014 to 56.5 percent in 2017 (Ghana Health Service, 2015). This had a ripple effect on the mortality rate in the country. The skilled delivery rate in deprived regions in Ghana still lags at a rate of $26.7 \%$. The home delivery rate in the country as of 2017 stands at $20.0 \%$, with rural regions having the highest proportion (UNICEF, 2017).

The West Mamprusi Municipality (WMM), which is the study area, has high home deliveries and most of these births often result in birth complications and deaths. Most women who deliver at home are usually attended to by old ladies and men, especially mothers-in-law, popularly known as Traditional Birth Attendants (TBAs) who are believed to have some experience in conducting deliveries at home. The majority of babies born at home in the Municipality stand the chance of missing out on lifesaving vaccines at birth, while umbilical cord care is poorly done at home leading to cord sepsis. The services of the TBAs are still preferred to SBAs because they are friendlier and understand the needs of women during childbirth (Tafere $e t$ $a l ., 2018)$. On the other hand, women criticize the poor quality of care provided in health facilities, both in terms of unreliability (e.g., being understaffed and under-supplied) and offering disrespectful treatment to women (Gebrehiwot, San Sebastian, Edin, \& Goicolea, 2014). The Municipal's annual performance review report (Ghana Health Service, 2017) revealed a $98 \%$ ANC coverage. Irrespective of this percentage, less than half $(46.1 \%)$ of the women delivered in health facilities.

Several maternal and child mortalities, as well as birth complications, could be avoided or managed successfully if pregnant women have access to a qualified birth attendant such as a doctor, nurse or midwife during delivery (Rawe, 2011).

Previous studies show that the utilization of facility-based delivery is usually affected by socio-cultural norms and several other factors including cost, long-distance, accessibility, availability, and quality of the services (Yaya et al., 2018). Women in low socio-economic status have no money for transportation during labor and this compels them to deliver at home (Egharevba, et al., 2017).

Even though ample studies have been conducted on health facilities deliveries, especially in Northern Ghana, there are no published studies conducted on facility deliveries in the WMM. Therefore, the purpose of this study was to explore the factors affecting utilization of health facilities for delivery by pregnant women in the WMM of Northern Ghana by adopting the three delays model. 


\section{Methods and Materials \\ Study Design}

The study was a cross-sectional household survey with 381 women in the age group 15-49 years, conducted from January to March 2019, in the WMM of Northern Ghana.

\section{Study Setting}

The study was conducted in the WMM, which is located in the Northern region of Ghana. The Municipality was created out of the Gambaga District in 1988 under the Government of Ghana's decentralization and local government reform policy. It is one of the 26 Municipalities in the northern region with Walewale as the administrative capital. Walewale lies on the Tamale-Bolgatanga trunk road, approximately 68 miles away from Tamale. According to the Ghana (2010) population and housing census, and the Ghana Statistical Service (2014), the Municipality has a total population of 147,953 made up of mostly Mamprusis who constitute about $75 \%$ of the total population. The Municipality shares boundaries with 11 Districts and 2 regions. It has four sub-districts and 150 communities.

There are three main ethnic groups (Mamprusis, Kantosis, and Comas) mixed with settlers such as Frafras, Kassenas, Builsas, Zambarimas, and Hausas. The most widely spoken language is Mampruli.

The inhabitants are mainly subsistence farmers who largely depend on natural rainfall to grow cowpea, millet, guinea corn, peanut, rice, and maize. Livestock rearing of cattle, goats, sheep, and local birds is also a common activity of the inhabitants.

According to the 2010 population and housing census, the population of women of reproductive age is 35,509 with total fertility of 3.6 and an average population growth rate of $2.9 \%$.

The Municipal health infrastructure is made up of one municipal hospital, a polyclinic, five clinics, eleven functional CHPS compounds, and two health centers. Nine facilities in the Municipality are currently offering BEmONC and CEmONC services.

\section{Study Population}

The study was conducted among women of reproductive age group (15-49) years who have delivered in a health facility or home in the WMM within one year before the study.

\section{Inclusion Criteria}

All women who delivered within one year before the study and stayed in the study area during the period of data collection were willing to take part 
in the study. Women with birth complications such as stillbirths and child death were also included in the study.

\section{Exclusion Criteria}

Women who lived in the study area for less than 6 months, who were severely ill, who gave birth more than one year before the study, and women aged $<15$ and $>49$ years were excluded from the study. Women who refused to participate due to socio-cultural reasons were also excluded.

\section{Sample Size Determination}

The sample size was determined based on the specific objectives, which focuses on estimating the proportion of facility delivery. Based on the Municipal annual review records, $46.1 \%$ of the women delivered in health facilities. Using a comparison of two proportions and using a baseline proportion $(46.1 \%)$ with a power of $80 \%$, Alpha $(\alpha)$ of 0.05 , Z-value of 1.28 , and expected difference of $15 \%$ gives a sample size of 346 using Stata. Ten percent $(10 \%)$ attrition rate adds up to $0.1 \times 346=34.6+346=381$. Thus, a sample size (n) of 381 mothers was enough to answer the study questions.

\section{Sampling Strategy}

The probability sampling method was used to recruit the respondents for this study. By referring to the health facilities delivery and PNC registers, the community health volunteers' registers and the District Health Information Management System (DHIMS) records, which shows a list of all women who delivered in the Municipality between the periods $21^{\text {st }}$ January 2018 and $6^{\text {th }}$ March 2019, was compiled. This gave a sample frame of 914 women, consisting of the facility and home deliveries. The list comprised of the following: name, age, place of birth (home and facility), date of delivery, and the contact addresses of the women.

Out of the sample frame of 914 women, randomization was conducted using Microsoft Excel software which gave a total sample of 381 women, consisting of 94 homes and 287 facility deliveries. Selected women were then traced with the help of community health volunteers and were interviewed.

\section{Study Variables and Conceptual Framework}

The conceptual framework used for this study deployed the concept of the three delays model of maternal healthcare utilization developed by Thaddeus and Maine. The model was restructured and used by Gabrysch and Campbell (2009) to distinguish emergency care-seeking and preferred place of delivery. The model was further altered to suit a study conducted by Kifle et al. (2018) to determine the choice of delivery place. In this study, there were some modifications to the model in terms of the variables. Some new variables 
have been added, while a few variables in the original model were also excluded.

In this study, the key-dependent variable was the place of delivery of the last birth in the last year. The place of delivery in this research was defined as either facility-based or home. Facility-based delivery is a delivery that occurs in a health care facility. Births that take place outside the health care facility were considered as home delivery.

The independent variable was categorized as; sociodemographic characteristics, Antenatal history, socio-economic characteristics, accessibility (time and distance to the facility), benefit/need, perception, and attitudinal variables.

Since the conceptual framework adopts the three delays model, it captures the sociodemographic characteristic (predisposing factors) associated with place of delivery as the first delay in seeking health care, factors associated with identifying and reaching health facility (enabling factors) as the second delay, and the factors related to receiving health care in the facility (perceived benefit/need) as the third delay.

The variables used to conceptualize the first delay were sociodemographic characteristics such as; maternal age, marital status, marital age, ethnic background, woman and partner educations, religious background, place of residence, birth order, Joint decision making, woman autonomy in decision making, and family size.

The variable used to conceptualize the second delay include; occupational status, type of employment, travel distance to the nearest health facility, traveling time to the nearest health facility, means of transport to the facility, possession of health insurance card, payment out of pocket, and amount of money earned in a month. The third delay conceptualized variables such as; ANC usage, the number of ANC visits, planned pregnancy, Weeks of pregnancy, the outcome of last pregnancy, the experience of past pregnancy complications, knowledge of pregnancy danger signs, family planning usage, level of satisfaction of last delivery place, the scale of satisfaction, and preferred place of next delivery. Figure 1. shows the conceptual framework of determinants of place of delivery by applying the three delays model (Kifle et al., 2018). 


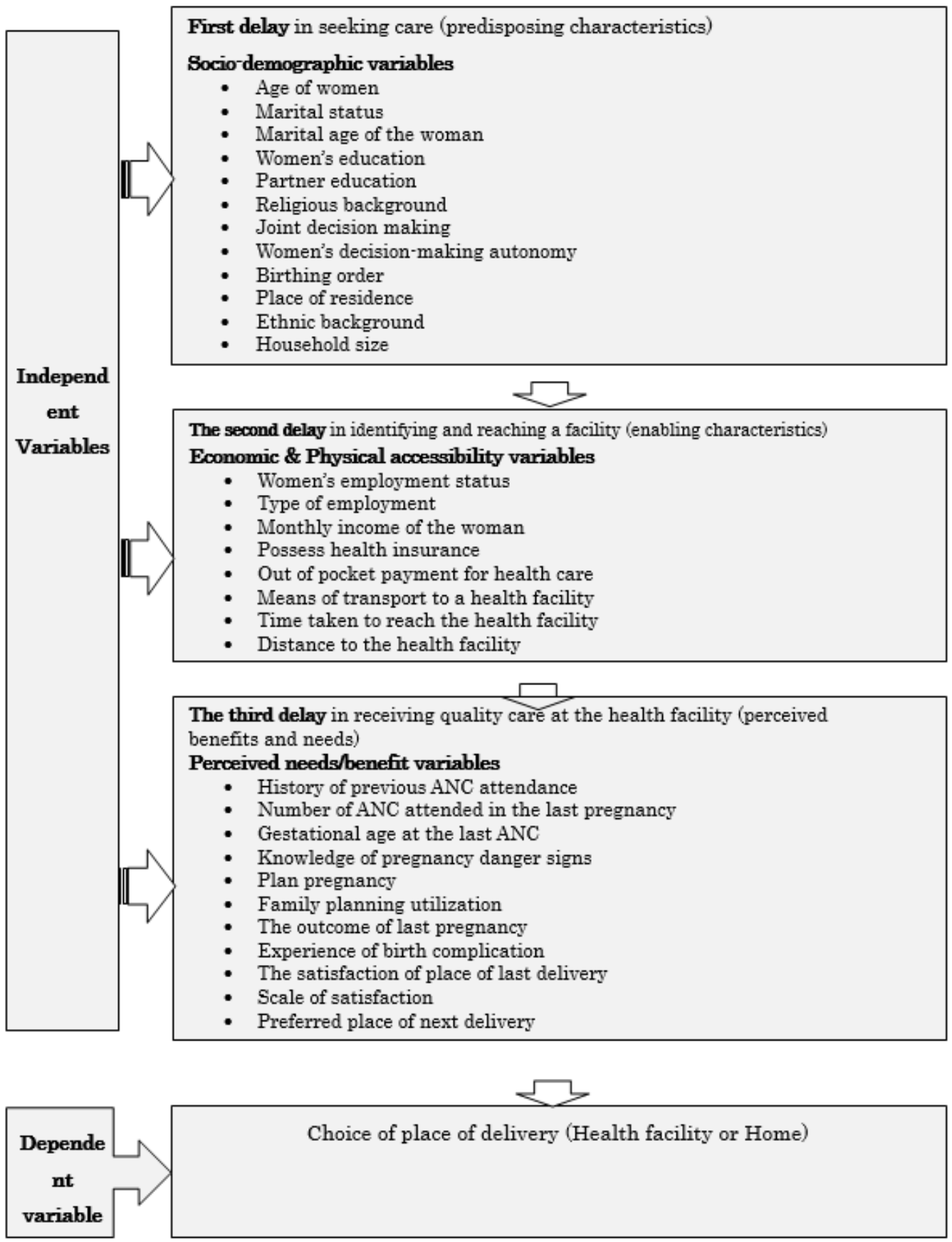

Figure 1. Conceptual framework of determinants of place of delivery by applying the three delays model Adapted from Kifle et al. (2018) 


\section{Data Collection Methods and Tools}

The data was collected using a structured questionnaire consisting of open and closed-ended questions. The questionnaires were pre-tested among $10 \%$ of women in a similar population setting for consistency and ease of administration. Queries were designed to solicit information such as: (1) the general socio-economic status of the Municipality, (2) challenges in accessing health care, (3) the most preferred facility, and (4) perception about the facility and home deliveries.

College graduates were recruited and trained as research assistants for the data collection. These assistants were given two days of training and were equipped with logistics needed for the data collection. The survey began at 08:00 hours GMT and ended at 17:00 hours GMT daily, approximately nine hours a day for 16 days. The data collectors moved from house to house to interview the respondents using the list of selected respondents. Respondents who met the inclusion criteria were given a brief explanation of the data collection processes and made to sign the informed consent form. Respondents who could not sign due to illiteracy were made to thumbprint. Revisits were made to households where respondents were absent at the first visit. Data were collected from January to March 2019.

\section{Data Processing}

Data collected from the field was cross-checked for abnormalities such as mistakes in age, date of birth, sex, unanswered questions, non-respondents, and missing questionnaires. The identification numbers on the questionnaires were also crossed-examined to ensure no double numbering. Pages of all questionnaires were inspected to see that all were intact. Mistakes discovered on the data collected were corrected and coding was done before data entry.

The data was entered using the international business machines, statistical package for the social sciences' (IBM-SPSS version 25) statistical software. Thereafter, it was exported to Stata (version. 15) statistical software for the analysis.

\section{Variable Description and Measure}

In conducting the analysis, the outcome variable for the study was the place of delivery. In this study, the dependent variable was coded as ' 1 ' if the woman gave birth at a health facility and coded as ' 0 ' if the woman delivered at home. Since the dependent variable was dichotomous, a discrete choice model was employed to show and explain the relationship between the outcome and the explanatory variables.

Overall, 35 explanatory variables were used: maternal age, maternal education, partner education, marital status, household size, birthing order, marital age of woman, religious background, ethnic background, place of 
residence, joint decision making, woman decision making autonomy, current employment, type of employment, monthly income, possession of national health insurance card, payment out of pocket, the distance to the health facility, time taken to reach the facility, means of transport, ANC attendance, number of ANC attended, gestational weeks, plan pregnancy, knowledge of danger signs, preferred next delivery place, birth complications, family planning, the favor of facility delivery, opinion on home delivery, challenges of facility delivery, care to seek when in danger, why women deliver at home, satisfaction with the place of delivery, and the scale of satisfaction.

Maternal age was categorized as: 15-19, 20-29, 30-39, and 40-49. Similarly, the number of younger women has been categorized as 1-4 and 5-8 and above.

Woman and partner education was categorized as 0-no-education, 1primary, 2-junior high school, 3-senior high school, and 4-higher institution. Marital status was categorized as 0-Never married, 1-Married, 2-living with partner, 3-divorced, and 4-widowed. The marital age of the woman was categorized as 15-19, 20-29, and 30-35. Family size was grouped as 2-4, 5-9, 10-14, and 15+. Religion was put at 0-Christianity and 1-Islam. Place of residence was either 0-rural, or 1-urban, while ethnicity was assembled as 0Mamprusi, 1-Frafra, 2-Moshi, and 3-Others. Joint decision making was categorized as 0-husband, 1-mother of the woman, 2-mother in-law, 3-father in-law, and 4-Self. Women's decision-making autonomy was categorized as 0 -yes and 1-no. Current employment was categorized as 0-yes and 1-no. Type of employment was grouped into 0-housewife, 1-Farmer, 2-Trader, 3-Civil servant, 4-Hairdresser, and 5-Seamstress. Possession of national health insurance card and payment out of pocket variables were categorized as 0-yes and 1-no. Distance to the health facility was put into $0-4 \mathrm{~km}, 5-8 \mathrm{~km}$, while time to the health facility was summed into $\leq 30 \mathrm{~min}, 31-60 \mathrm{~min}, 61-90 \mathrm{~min}$, and 91 $120 \mathrm{~min}$. Means of transport were categorized as 0-Bicycle, 1-By foot, 2-Car, 3-Donkey cart, 4-Motor bike, and 5-Tricycle. ANC attended during pregnancy, plan pregnancy, satisfaction of delivery place, birth complications, and family planning usage were all categorized as 0 -yes and 1-no, while the number of ANC attended was 1-4, 5-9, 10+, and can't remember. The scale of satisfaction was categorized as 0-very satisfied, 1-satisfied, 2-somehow satisfied, 3-not satisfied, 4- never satisfied, while gestational age at ANC was grouped under 1-12, 13-24, and 25-36. The outcome of the last pregnancy was grouped as 0-live birth and 1-birth complications. Knowledge of danger signs was categorized as 0-knowledgeable and 1-not knowledgeable. The preferred place of next delivery was categorized as 0-Health facility, 1-TBAs/home, and 2-Not sure. 


\section{Statistical Analysis}

In carrying out the data analysis, simple descriptive statistics and Chisquare tests were performed. In the descriptive analysis, frequency distribution and percentages were conducted to describe the demographic, socioeconomic, perception, and behavior variables in the study.

In the Chi-square test, a bivariate analysis was carried out to identify factors that affect the choice of delivery place. Also, a multivariate logistic regression analysis was performed to identify the variables associated with facility delivery. In conducting the multivariate analysis, explanatory variables were included in the model if they were statistically significant with the place of delivery with a cut-off $\mathrm{p}$-value of $<0.05$. Additionally, the likelihood ratio test (LRT) was conducted on the multivariate logistic regression model to choose the best fit model for this study.

Odds ratio $(\mathrm{OR})$ was defined in this research as follows: $\mathrm{OR}=1$ implies there is no difference, whereas $\mathrm{OR}>1$ shows respondents were more likely to deliver in a health facility, and OR $<1$ shows respondents were less likely to deliver in a facility.

Statistical tests were set at a 5\% level of significance with a $95 \%$ confidence interval. All analysis was conducted using the Stata version 15 statistical software. The results were presented in frequency tables and proportions.

\section{Data Management/Storage}

Personal data in soft copy form were kept in a secure database with a password known only to the researchers and the university. Printed and hardware data were stored safely in the university under lock and key. Data on the hardcopy form were also under lock and key in Ghana. Data records were kept safely in a cabinet and locked and would be destroyed one year after writing the thesis.

\section{Quality Control}

Two days of intensive training was given to data collectors to ensure they have prerequisite knowledge of the research work and the data collection process. The questionnaire was pre-tested among $10 \%$ of women in a similar population setting for consistency and ease of administration. Minor changes were made before data collection. Keen supervision of the data collection process was also done. Each team of data collectors was closely followed-up to ensure that they were doing what was expected of them. At the end of each day, filled questionnaires were cross-checked for proper answering. Also, most parts of the questionnaire were adapted from the demographic and health survey questionnaires and other similar studies. 


\section{Ethical Consideration}

Ethical approval was granted by the Nagasaki University Ethical Review Committee (Protocol approval number: 051, Approval date: 27th September, 2018) and the Navrongo Health Research Centre Institutional Review Board of Ghana (Approval number: NHRCIRB324, Approval date: 12th November, 2018).

Written permission to carry out the study was sought from the Municipal health authorities as well as traditional and opinion leaders. Participants who agreed to participate were made to sign or thumbprint an informed consent form.

\section{Informed Consent and Confidentiality of Study Participants}

Written consent was compiled that spelled out the details of the study to interviewees in their preferred language. The purpose of the study, the procedures, as well as the risks and benefits of participating were explained thoroughly to the respondents. Participation was voluntary. Therefore, all participants reserve the right to participate or withdraw from the study at any time or skip any question that they do not wish to answer without any consequences. Participants were assured that the data would be reported in aggregate form and shall not be associated with individual households or families in the community. All participants were assured their records would only be made available to the researchers and no third party would have the chance of seeing them. They were also informed that their records will be kept safely in a cabinet and locked, which would be destroyed a year after writing the thesis. Literate participants were asked to sign a copy of the consent form. Non-literate participants were made to thumbprint on the signature line. For participants who were less than 18 years of age, consent was sought from their legal guardians.

\section{Risk and Benefit of the Study}

This study was noninvasive. Participants were at minimal risk of being part of the study. Nonetheless, participants were asked about their birthing experience and this made them feel a little uncomfortable. The researchers ensured that any act that could lead participants to risk was professionally handled. The potential benefit to the health service provider is to enhance proper service delivery, while the participant benefits indirectly and for a longterm from improved maternal and neonatal health service delivery in the Municipality. 


\section{Payment for Participation}

Participants were not made to pay in any form to participate, neither were they paid any amount either in cash or in-kind as compensation for participating in the study.

\section{Declaration of Interest}

The researchers of this study have no commercial interest in the outcome and the implementation of the study results. Henceforth, all authors declare no competing interests. In case of an unseen conflict of interest later during and after the study, pragmatic measures would be taken to forestall it.

\section{Results}

\section{Socio-demographic Characteristics of the Respondents}

A total number of 381 women were recruited and interviewed for this study. The mean age of the respondents was $27.5 \pm 6.1$ years. More than half (56.4\%) of the respondents were in the age range of 20-29 years. Regarding educational status, majority of the respondents $(38.1 \%)$, as well as their partners $(42.8 \%)$, had no formal education. Of the respondents, $86.4 \%$ were married, and the marital age of most respondents (51.5\%) was between 20-29 years with a mean age of $20.2 \pm 3.5$ years. Most households of the respondents (64.8\%) contain between 5-9 people with a mean of 7.4 \pm 2.67 people. In terms of parity, more than three-quarters $(78.7 \%)$ of the respondents had between 14 children with a mean number of $2.9 \pm 1.9$ children. Of the respondents, $80.1 \%$ were Islamic worshippers, $87.7 \%$ belongs to the Mamprusi ethnic group, and $78.7 \%$ were rural dwellers. On decision making before seeking health care, $80.3 \%$ of the respondents' husbands have the final decision-making power. The detailed socio-demographic information is displayed in Table 1.

Table 1. Sociodemographic characteristics of the respondents

\begin{tabular}{|c|c|c|c|c|}
\hline \multirow[b]{2}{*}{ Characteristics } & \multirow{2}{*}{$\begin{array}{c}\text { Total } \\
\text { n } \\
(\mathbf{3 8 1})\end{array}$} & \multicolumn{2}{|c|}{ Place of delivery } & \multirow[b]{2}{*}{ p-value } \\
\hline & & $\begin{array}{l}\text { Facility } \\
287(75.3 \%)\end{array}$ & $\begin{array}{c}\text { Home } \\
94(24.7 \%) \\
\end{array}$ & \\
\hline Age (years) of mother: & & & & 0.008 \\
\hline $15-19$ & $9.4 \%$ & $11.5 \%$ & $3.2 \%$ & \\
\hline $20-29$ & $56.4 \%$ & $58.2 \%$ & $51.1 \%$ & \\
\hline $30-39$ & $29.9 \%$ & $27.2 \%$ & $38.3 \%$ & \\
\hline $40-49$ & $4.3 \%$ & $3.1 \%$ & $7.4 \%$ & \\
\hline & Mean \pm SD $^{1}: 27.5 \pm 6.1$ & & & \\
\hline Women's education: & & & & $<0.001$ \\
\hline No education & $38.1 \%$ & $33.8 \%$ & $51.1 \%$ & \\
\hline Primary & $18.9 \%$ & $17.8 \%$ & $22.2 \%$ & \\
\hline $\mathrm{JHS}^{1}$ & $25.4 \%$ & $25.8 \%$ & $24.5 \%$ & \\
\hline SHS $^{2}$ & $14.2 \%$ & $18.5 \%$ & $1.1 \%$ & \\
\hline Higher (Tertiary) & $3.4 \%$ & $4.1 \%$ & $1.1 \%$ & \\
\hline Partner's education: & & & & 0.007 \\
\hline No education & $42.8 \%$ & $38.7 \%$ & $55.4 \%$ & \\
\hline Primary & $9.4 \%$ & $8.0 \%$ & $13.8 \%$ & \\
\hline
\end{tabular}


February 2021 edition Vol.17, No.7

\begin{tabular}{|c|c|c|c|c|}
\hline JHS & $11.0 \%$ & $12.2 \%$ & $7.5 \%$ & \\
\hline SHS & $19.7 \%$ & $22.6 \%$ & $10.6 \%$ & \\
\hline Higher (Tertiary) & $15.5 \%$ & $17.1 \%$ & $10.6 \%$ & \\
\hline Don't know & $1.6 \%$ & $1.4 \%$ & $2.1 \%$ & \\
\hline \multicolumn{4}{|l|}{ Marital status: } & 0.009 \\
\hline Never married & $0.8 \%$ & $0.4 \%$ & $2.1 \%$ & \\
\hline Married & $86.4 \%$ & $84.2 \%$ & $92.5 \%$ & \\
\hline Cohabiting & $11.7 \%$ & $14.3 \%$ & $4.3 \%$ & \\
\hline Divorced & $0.3 \%$ & $0.0 \%$ & $1.1 \%$ & \\
\hline Widowed & $0.8 \%$ & $1.1 \%$ & $0.0 \%$ & \\
\hline \multicolumn{4}{|l|}{ Marital age of woman: } & 0.59 \\
\hline $15-19$ & $46.7 \%$ & $47.7 \%$ & $43.6 \%$ & \\
\hline $20-29$ & $51.5 \%$ & $50.2 \%$ & $55.3 \%$ & \\
\hline \multirow[t]{2}{*}{$30-35$} & $1.8 \%$ & $2.1 \%$ & $1.1 \%$ & \\
\hline & Mean \pm SD: $20.2 \pm 3.5$ & & & \\
\hline \multicolumn{4}{|l|}{ Household size: } & 0.41 \\
\hline $2-4$ & $13.6 \%$ & $14.6 \%$ & $10.6 \%$ & \\
\hline $5-9$ & $64.8 \%$ & $63.1 \%$ & $80.5 \%$ & \\
\hline $10-14$ & $21.0 \%$ & $21.9 \%$ & $8.6 \%$ & \\
\hline \multirow[t]{2}{*}{$15+$} & $0.5 \%$ & $0.4 \%$ & $0.3 \%$ & \\
\hline & Mean \pm SD:7.4 \pm 2.67 & & & \\
\hline \multicolumn{4}{|l|}{ Parity: } & 0.56 \\
\hline $1-4$ & $78.7 \%$ & $79.4 \%$ & $76.6 \%$ & \\
\hline \multirow[t]{2}{*}{$5-8$} & $21.3 \%$ & $20.6 \%$ & $23.4 \%$ & \\
\hline & Mean \pm SD:2.9 \pm 1.9 & & & \\
\hline Religion: & & & & 0.21 \\
\hline Christian & $19.9 \%$ & $18.5 \%$ & $24.5 \%$ & \\
\hline Islam & $80.1 \%$ & $81.5 \%$ & $75.5 \%$ & \\
\hline \multicolumn{4}{|l|}{ Ethnicity: } & 0.02 \\
\hline Mamprusi & $87.7 \%$ & $90.6 \%$ & $78.6 \%$ & \\
\hline Frafra & $5.5 \%$ & $4.5 \%$ & $9.1 \%$ & \\
\hline Moshi & $2.3 \%$ & $1.1 \%$ & $6.2 \%$ & \\
\hline Others & $4.5 \%$ & $3.8 \%$ & $6.1 \%$ & \\
\hline \multicolumn{4}{|l|}{ Place of residence: } & 0.56 \\
\hline Rural & $78.7 \%$ & $78.1 \%$ & $80.9 \%$ & \\
\hline Urban & $21.3 \%$ & $21.9 \%$ & $19.1 \%$ & \\
\hline \multicolumn{4}{|l|}{ Joint decision making: } & 0.29 \\
\hline Husband & $80.3 \%$ & $79.2 \%$ & $84.0 \%$ & \\
\hline $\begin{array}{l}\text { Mother of the } \\
\text { woman }\end{array}$ & $2.9 \%$ & $2.4 \%$ & $4.3 \%$ & \\
\hline Mother-in-law & $9.7 \%$ & $11.5 \%$ & $4.3 \%$ & \\
\hline Father-in-law & $5.3 \%$ & $5.2 \%$ & $5.3 \%$ & \\
\hline Myself & $1.8 \%$ & $1.7 \%$ & $2.1 \%$ & \\
\hline \multirow{2}{*}{\multicolumn{4}{|c|}{$\begin{array}{l}\text { Women's decision making } \\
\text { autonomy: }\end{array}$}} & \\
\hline & & & & 0.81 \\
\hline Yes & $37.3 \%$ & $36.9 \%$ & $38.3 \%$ & \\
\hline No & $62.7 \%$ & $63.1 \%$ & $61.7 \%$ & \\
\hline
\end{tabular}

${ }^{1}$ SD Standard deviation ${ }^{2} \mathrm{JHS} \sim$ Junior high school ${ }^{3}$ SHS Senior high school 


\section{Economic and Physical Accessibility Variables related to Identifying and Reaching the Nearest Health Facility}

Table 2 shows the Economic and Physical accessibility variables related to identifying and reaching the nearest health facility.

Out of the 381 respondents, $55.4 \%$ were employed, $45.4 \%$ were housewives, $23.4 \%$ were farmers while a few $(3.4 \%)$ were civil servants. An appreciable number of the respondents $(56.7 \%)$ could not remember how much they earn in a month while $21.3 \%$ earn an income of less than 10 US\$ per month. Concerning payment before receiving ANC and Delivery care, a vast number of the respondents $(96.6 \%)$ had a national health insurance card, and $28.6 \%$ of the respondents paid out of their pocket to receive health care. Proximity-wise, the majority of the respondents $(80.1 \%)$ travel a distance between $0-4 \mathrm{~km}$ to the nearest health facility, it takes between 0-30 minutes travel time by many respondents $(61.7 \%)$ to reach the nearest health facility, while more than half $(55.6 \%)$ of the respondents travel by foot to the nearest health facility.

Table 2. Economic and physical accessibility characteristics related to identifying and reaching the nearest health facility

\begin{tabular}{|c|c|c|c|c|}
\hline \multirow[b]{2}{*}{ Characteristics } & \multirow{2}{*}{$\begin{array}{c}\text { Total } \\
\mathbf{n} \\
(\mathbf{3 8 1})\end{array}$} & \multicolumn{2}{|c|}{ Place of delivery } & \multirow[b]{2}{*}{ p-value } \\
\hline & & $\begin{array}{l}\text { Facility } \\
287(75.3 \%)\end{array}$ & $\begin{array}{l}\text { Home } \\
94(24.7 \%)\end{array}$ & \\
\hline Currently, employed? & & & & 0.24 \\
\hline No & $44.6 \%$ & $46.3 \%$ & $39.4 \%$ & \\
\hline Yes & $55.4 \%$ & $53.7 \%$ & $60.6 \%$ & \\
\hline Type of employment: & & & & 0.06 \\
\hline Housewife (not employed) & $45.4 \%$ & $48.1 \%$ & $37.2 \%$ & \\
\hline Famer & $23.4 \%$ & $19.9 \%$ & $34.0 \%$ & \\
\hline Trader & $13.2 \%$ & $12.4 \%$ & $14.9 \%$ & \\
\hline Civil servant & $3.4 \%$ & $4.2 \%$ & $1.1 \%$ & \\
\hline Hairdresser & $6.0 \%$ & $6.3 \%$ & $5.3 \%$ & \\
\hline Seamstress & $8.6 \%$ & $9.1 \%$ & $7.5 \%$ & \\
\hline Monthly Income: & & & & 0.19 \\
\hline$<9.3 \mathrm{US}^{1}$ & $21.3 \%$ & $20.9 \%$ & $22.3 \%$ & \\
\hline 9.3-20.2US\$ & $11.0 \%$ & $11.2 \%$ & $10.6 \%$ & \\
\hline 20.4-92.5US\$ & $6.8 \%$ & $5.2 \%$ & $11.7 \%$ & \\
\hline 92.6-203.6US\$ & $3.9 \%$ & $4.9 \%$ & $1.1 \%$ & \\
\hline 204US\$ and above & $0.3 \%$ & $0.4 \%$ & $0.0 \%$ & \\
\hline Cannot remember & $56.7 \%$ & $57.4 \%$ & $54.3 \%$ & \\
\hline Possession of $\mathrm{NHI}^{2}$ Card: & & & & 0.85 \\
\hline Yes & $96.6 \%$ & $97.0 \%$ & $96.3 \%$ & \\
\hline No & $3.4 \%$ & $3.0 \%$ & $3.7 \%$ & \\
\hline Paid out of pocket: & & & & 0.04 \\
\hline No & $54.9 \%$ & $37.6 \%$ & $22.3 \%$ & \\
\hline Partially & $16.5 \%$ & $38.6 \%$ & $29.6 \%$ & \\
\hline Yes & $28.6 \%$ & $23.8 \%$ & $48.1 \%$ & \\
\hline Distance $\left(\mathrm{km}^{3}\right)$ to nearest facility: & & & & 0.56 \\
\hline $0-4 \mathrm{~km}$ & $80.1 \%$ & $79.1 \%$ & $82.9 \%$ & \\
\hline $5-8 \mathrm{~km}$ & $19.4 \%$ & $20.3 \%$ & $17.1 \%$ & \\
\hline Do not know & $0.5 \%$ & $0.6 \%$ & $0.0 \%$ & \\
\hline Time $\left(\min ^{4}\right.$.) to the nearest facility: & & & & 0.95 \\
\hline
\end{tabular}




\begin{tabular}{|c|c|c|c|c|}
\hline $0-30 \mathrm{~min}$ & $61.7 \%$ & $61.3 \%$ & $62.8 \%$ & \\
\hline $31-60 \mathrm{~min}$ & $30.7 \%$ & $31.1 \%$ & $28.7 \%$ & \\
\hline $61-90 \min$ & $6.6 \%$ & $6.1 \%$ & $7.4 \%$ & \\
\hline $91-120 \mathrm{~min}$ & $1.0 \%$ & $1.5 \%$ & $1.1 \%$ & \\
\hline Means of transport to the facility: & & & & $<0.001$ \\
\hline Bicycle & $3.9 \%$ & $2.1 \%$ & $9.6 \%$ & \\
\hline By foot & $55.6 \%$ & $57.1 \%$ & $51.1 \%$ & \\
\hline Car & $9.9 \%$ & $10.5 \%$ & $8.5 \%$ & \\
\hline Donkey cart & $0.3 \%$ & $0.4 \%$ & $0.0 \%$ & \\
\hline Motorbike & $23.1 \%$ & $20.6 \%$ & $30.8 \%$ & \\
\hline Tricycle & $7.2 \%$ & $9.3 \%$ & $0.0 \%$ & \\
\hline
\end{tabular}

\section{Variables Related to Perceived Needs/Benefits for Receiving Health Care}

Table 3 depicts the factors related to perceived needs/benefits of receiving health care. Of the respondents, $98.2 \%$ attended ANC during their last pregnancy, while $76.8 \%$ made more than 4 ANC visits. A high percentage of the respondents $(73.4 \%)$ were between 1-12 weeks pregnant at their first ANC visit. Quite a multitude of the respondents (83.9\%) had planned their last pregnancies. Almost every respondent $(99.5 \%)$ had a safe birth outcome in their last pregnancies. Most of the respondents (55.9\%) had inadequate knowledge about the danger signs of pregnancy. On the issues of satisfaction of the last place of delivery, $93.2 \%$ of the respondents were satisfied. Nine out of ten $(90 \%)$ of the respondents prefer to deliver their next child in a health facility. A high number of respondents (69.3\%) did not experience any birth complications during their last childbirth. Regarding birth spacing, a greater portion of the respondents $(71.1 \%)$ never used a family planning method.

Table 3. Factors related to perceived needs/benefits for receiving health care

\begin{tabular}{|c|c|c|c|c|}
\hline \multirow[b]{2}{*}{ Characteristics } & \multirow{2}{*}{$\begin{array}{c}\text { Total } \\
\mathbf{n} \\
(\mathbf{3 8 1})\end{array}$} & \multicolumn{2}{|c|}{ Place of delivery } & \multirow[b]{2}{*}{ p-value } \\
\hline & & $\begin{array}{l}\text { Facility } \\
287(75.3 \%)\end{array}$ & $\begin{array}{l}\text { Home } \\
94(24.7 \%)\end{array}$ & \\
\hline ANC attendance: & & & & 0.75 \\
\hline No & $1.6 \%$ & $1.4 \%$ & $2.1 \%$ & \\
\hline Yes & $98.2 \%$ & $98.3 \%$ & $97.9 \%$ & \\
\hline Cannot remember & $0.2 \%$ & $0.3 \%$ & $0.0 \%$ & \\
\hline Number of ANC attendance $(n=354)$ & & & & 0.004 \\
\hline $1-4$ & $17.3 \%$ & $13.0 \%$ & $30.6 \%$ & \\
\hline $5-9$ & $76.8 \%$ & $80.7 \%$ & $64.7 \%$ & \\
\hline $10+$ & $1.4 \%$ & $1.5 \%$ & $1.2 \%$ & \\
\hline Cannot remember & $4.5 \%$ & $4.8 \%$ & $3.5 \%$ & \\
\hline Gestational age at first $\operatorname{ANC}(n=342)$ : & & & & 0.09 \\
\hline 1-12weeks & $73.4 \%$ & $75.8 \%$ & $65.4 \%$ & \\
\hline 13-24weeks & $22.5 \%$ & $21.1 \%$ & $27.2 \%$ & \\
\hline 25-36weeks & $4.1 \%$ & $3.1 \%$ & $7.4 \%$ & \\
\hline Planned pregnancy (wanted)? & & & & 0.34 \\
\hline No & $16.1 \%$ & $14.9 \%$ & $19.1 \%$ & \\
\hline Yes & $83.9 \%$ & $85.1 \%$ & $80.9 \%$ & \\
\hline The outcome of last pregnancy: & & & & 0.41 \\
\hline Live birth (safe delivery) & $99.5 \%$ & $99.7 \%$ & $98.9 \%$ & \\
\hline Birth complications to mother & $0.5 \%$ & $0.3 \%$ & $1.1 \%$ & \\
\hline Knowledge of danger signs ${ }^{1}$ : & & & & 0.54 \\
\hline
\end{tabular}




\begin{tabular}{lllll} 
Not knowledgeable & $55.9 \%$ & $56.8 \%$ & $53.2 \%$ & \\
$\begin{array}{l}\text { Knowledgeable } \\
\text { Satisfied with the place of delivery? }\end{array}$ & $44.1 \%$ & $43.2 \%$ & $44.8 \%$ & 0.002 \\
No & $5.5 \%$ & $3.5 \%$ & $11.7 \%$ & \\
Yes & $93.2 \%$ & $95.8 \%$ & $85.1 \%$ & \\
$\quad$ Not sure & $1.3 \%$ & $0.7 \%$ & $3.2 \%$ & $<0.001$ \\
The scale of satisfaction: & & & & \\
$\quad$ Very satisfied & $59.4 \%$ & $66.4 \%$ & $37.7 \%$ & \\
$\quad$ Satisfied & $25.9 \%$ & $25.2 \%$ & $27.9 \%$ & \\
$\quad$ Somehow satisfied & $7.9 \%$ & $4.6 \%$ & $18.3 \%$ & \\
$\quad$ Not satisfied & $3.9 \%$ & $2.1 \%$ & $9.7 \%$ & \\
$\quad$ Never satisfied & $2.1 \%$ & $1.7 \%$ & $3.2 \%$ & \\
$\quad$ I don't know & $0.8 \%$ & $0.0 \%$ & $3.2 \%$ & \\
Preferred place of next delivery: & & & & \\
Health facility & $90.0 \%$ & $93.4 \%$ & $79.4 \%$ & \\
$\quad$ TBAs home & $0.8 \%$ & $0.0 \%$ & $1.0 \%$ & \\
$\quad$ Home & $7.9 \%$ & $5.5 \%$ & $18.1 \%$ & \\
$\quad$ Not sure yet & $1.3 \%$ & $1.1 \%$ & $1.5 \%$ & \\
History of birth complications ${ }^{2}:$ & & & & \\
$\quad$ No & $69.3 \%$ & $66.2 \%$ & $78.7 \%$ & \\
$\quad$ Yes & $30.7 \%$ & $33.8 \%$ & $21.3 \%$ & \\
Family planning utilization: & & & & \\
$\quad$ No & $71.1 \%$ & $73.5 \%$ & $63.8 \%$ & \\
$\quad$ Yes & $28.9 \%$ & $26.5 \%$ & $36.2 \%$ & \\
\hline
\end{tabular}

\footnotetext{
${ }^{1}$ Knowledge of danger signs, if the respondent were able to mention at least four or more danger signs they were categorized as knowledgeable. ${ }^{2}$ Birth complications include obstructed labor, stillbirth
}

\section{Behaviour, Perceptions, and Attitudes of Women towards the Place of Delivery}

Table 4 displays the behavior, perceptions, and attitudes of women towards facility-based or home delivery. Majority of the respondents (93.7\%) favors the use of health facility for childbirth. A little above one-quarter (25.5\%) of the respondents stated that disrespect by health care providers is the major reason why women deliver at home. Most of the respondents (45.1\%) think home delivery is bad because of fear of complications and death. With regards to the place to seek care when in danger, a vast number of the respondents $(92.1 \%)$ prefer to seek the services of health care personnel.

Table 4. Behavior, perceptions, and attitudes of women towards the place of delivery

\begin{tabular}{|c|c|c|c|c|}
\hline \multirow[b]{2}{*}{ Characteristics } & \multirow{2}{*}{$\begin{array}{c}\text { Total } \\
\mathbf{n} \\
(\mathbf{3 8 1})\end{array}$} & \multicolumn{2}{|c|}{ Place of delivery } & \multirow[b]{2}{*}{ p-value } \\
\hline & & $\begin{array}{l}\text { Facility } \\
287(75.3 \%)\end{array}$ & $\begin{array}{l}\text { Home } \\
94(24.7 \%)\end{array}$ & \\
\hline Do you favor facility delivery? & & & & 0.008 \\
\hline No & $4.7 \%$ & $2.4 \%$ & $11.7 \%$ & \\
\hline Yes & $93.7 \%$ & $97.2 \%$ & $82.9 \%$ & \\
\hline I do not know & $1.6 \%$ & $0.4 \%$ & $5.4 \%$ & \\
\hline Reasons for home delivery: & & & & 0.003 \\
\hline Fear of operation at a hospital & $4.9 \%$ & $3.6 \%$ & $3.5 \%$ & \\
\hline Proper TBAs delivery at home & $2.9 \%$ & $5.9 \%$ & $5.4 \%$ & \\
\hline Long-distance to health facilities & $11.9 \%$ & $12.9 \%$ & $17.9 \%$ & \\
\hline Poor care by health staff & $18.6 \%$ & $18.5 \%$ & $20.9 \%$ & \\
\hline
\end{tabular}


Lack of financial support

Disrespect by health staff

Ignorance

Unexpected delivery at home

Do you think home delivery is good?

No, because of poor home care service

No, because of birth complication

Yes, because of proper care by TBA

Yes, a comfortable home environment

Yes, no money is required

No response

$\begin{array}{lll}15.6 \% & 15.3 \% & 21.9 \% \\ 25.5 \% & 22.2 \% & 4.6 \% \\ 5.6 \% & 4.2 \% & 11.4 \% \\ 15.9 \% & 17.4 \% & 14.7 \% \\ & & \\ 45.1 \% & 47.4 \% & 38.3 \% \\ 28.9 \% & 32.0 \% & 20.2 \% \\ 5.7 \% & 2.7 \% & 14.9 \% \\ 7.1 \% & 4.9 \% & 13.8 \% \\ 1.1 \% & 1.0 \% & 1.1 \% \\ 12.1 \% & 12.0 \% & 11.7 \%\end{array}$

0.001

Where to seek care when in danger:

Health personnel

TBA

$92.1 \%$

$3.9 \%$

$95.1 \%$

$1.7 \%$

$0.3 \%$

$0.0 \%$

BA healer

$0.5 \%$

Husband

$3.2 \%$

$0.4 \%$

$2.8 \%$

$82.9 \%$

$10.6 \%$

$1.1 \%$

$1.1 \%$

$4.3 \%$

\section{Bivariate and Multivariate Logistic Regression Results}

Table 5 exhibits the Bivariate and Multivariate logistics regression analysis of factors associated with health facility delivery. Concerning the bivariate regression analysis, maternal age $(\mathrm{OR}=8.56)$ and mother educational level $(\mathrm{OR}=4.42)$ were found to increase the likelihood of facility delivery. The travel time to the nearest health facility $(\mathrm{OR}=1.12)$ was also observed to be associated with delivery in a health facility. The number of ANC visits made by women $(\mathrm{OR}=2)$ was associated with health facility delivery. Again, women who were satisfied with facility delivery $(\mathrm{OR}=5.16)$ and those who prefer to deliver their next child in a facility $(\mathrm{OR}=2.38)$ were associated with facility delivery.

In terms of the multivariate logistic regression model, younger women, especially those in the age range of 15-19 years, were ten times [Adjusted Odds Ratio $(A O R)=10.21 ; 95 \%$ CI:1.83-56.99] more likely to deliver in a health facility. Respondents with a high level of educational attainment were almost four times [AOR=3.66; 95\% CI:1.19-68.9] more likely to deliver their children in a health facility. However, there was no significant difference between secondary education and higher education. Respondents with shorter travel time to the nearest health facility have a high chance $[\mathrm{AOR}=1.05 ; 95 \%$ $\mathrm{CI}: 1.57-1.95]$ to deliver in a health facility than those with longer travel time. In terms of ANC coverage, women who made more ANC contacts with health care providers have a higher probability [AOR $=1.17 ; 95 \% \mathrm{CI}: 1.04-36.7]$ of delivering in a health facility than those who made less or no contact. Respondents who expressed satisfaction in their last place of delivery and those who wish to deliver their next child in a health facility were $1[\mathrm{AOR}=1.81 ; 95 \% \mathrm{CI}: 1.22-14.81]$ and 1 [AOR=1.32; 95\% CI:1.19-8.97] times more likely to deliver in health facility respectively. 
Table 5. Bivariate and Multivariate logistics regression analysis of factors associated with health facility delivery

\begin{tabular}{|c|c|c|c|c|c|}
\hline \multirow{2}{*}{ Characteristics } & \multirow{2}{*}{$\begin{array}{c}\text { Facility } \\
\text { delivery } \\
\text { (\%) }\end{array}$} & \multicolumn{3}{|c|}{ Odds ratio $(95 \% \mathrm{CI})$} & \multirow[b]{2}{*}{ P-value } \\
\hline & & Crude & P-value & Adjusted & \\
\hline \multicolumn{6}{|l|}{ Age (years) of mother: } \\
\hline $15-19$ & $91.6 \%$ & $8.56(1.83-39.9)$ & 0.006 & $10.21(1.83-56.99)$ & 0.008 \\
\hline $20-29$ & $77.6 \%$ & $2.71(2.95-7.65)$ & 0.06 & $3.22(1.96-10.75)$ & 0.06 \\
\hline $30-39$ & $68.4 \%$ & $1.69(1.58-4.88)$ & 0.33 & $2.53(1.75-8.55)$ & 0.14 \\
\hline $40-49$ & $56.3 \%$ & 1 & & 1 & \\
\hline \multicolumn{6}{|c|}{ Mother's educational level: } \\
\hline No education & $66.9 \%$ & $0.17(2.02-1.33)$ & 0.09 & $0.16(1.02-1.46)$ & 0.11 \\
\hline Primary & $70.8 \%$ & $0.22(1.025-1.65)$ & 0.13 & $0.19(0.02-1.83)$ & 0.15 \\
\hline JHS & $76.3 \%$ & $0.27(0.03-2.17)$ & 0.11 & $0.25(0.03-2.30)$ & 0.22 \\
\hline SHS & $98.1 \%$ & $4.42(2.26-75.73)$ & 0.30 & $3.66(1.19-68.9)$ & 0.39 \\
\hline Higher (Tertiary) & $92.3 \%$ & 1 & & 1 & \\
\hline \multicolumn{6}{|c|}{$\begin{array}{l}\text { Time (min.) to the nearest health } \\
\text { facility: }\end{array}$} \\
\hline $0-30$ min & $74.9 \%$ & 1 & & 1 & \\
\hline $31-60 \mathrm{~min}$ & $76.9 \%$ & $1.12(3.66-1.88)$ & 0.68 & $1.05(1.57-1.95)$ & 0.87 \\
\hline $61-90 \mathrm{~min}$ & $72.0 \%$ & $0.86(0.34-2.17)$ & 0.75 & $0.44(0.14-1.36)$ & 0.16 \\
\hline $91-120 \mathrm{~min}$ & $75.0 \%$ & $1.00(2.10-9.85)$ & $<0.001$ & $0.35(1.02-6.23)$ & 0.47 \\
\hline \multicolumn{6}{|c|}{$\begin{array}{l}\text { Number of ANC attendance } \\
(n=374)\end{array}$} \\
\hline $1-4$ & $57.9 \%$ & $0.67(1.11-3.96)$ & 0.66 & $0.43(0.06-2.88)$ & 0.38 \\
\hline $5-9$ & $80.6 \%$ & $1.97(1.35-11.05)$ & 0.44 & $1.16(2.18-7.39)$ & 0.87 \\
\hline $10+$ & $80.1 \%$ & $2(2.13-31.98)$ & 0.62 & $1.17(1.04-36.7)$ & 0.93 \\
\hline Cannot remember & $80.0 \%$ & 1 & & 1 & \\
\hline \multicolumn{6}{|c|}{$\begin{array}{l}\text { Satisfied with the place of } \\
\text { delivery? }\end{array}$} \\
\hline No & $45.5 \%$ & $1.36(1.19-9.91)$ & 0.76 & $0.57(0.56-5.85)$ & 0.63 \\
\hline Yes & $77.5 \%$ & $5.16(1.85-31.4)$ & 0.08 & $1.81(1.22-14.81)$ & 0.58 \\
\hline Do not know & $40.0 \%$ & 1 & & 1 & \\
\hline \multicolumn{6}{|c|}{$\begin{array}{l}\text { Preferred place of next delivery: } \\
\text { Health facility }\end{array}$} \\
\hline TBAs home & $78.1 \%$ & $2.38(2.39-14.52)$ & 0.34 & $1.32(1.19-8.97)$ & 0.78 \\
\hline Home & $0.00 \%$ & 1 & & 1 & 0.89 \\
\hline & $43.3 \%$ & $0.51(0.74-3.51)$ & 0.49 & $0.37(0.05-3.03)$ & 0.35 \\
\hline
\end{tabular}




\section{Discussion}

The study aimed to assess the factors associated with the choice of place of delivery among women living in rural Northern Ghana. This study explored the factors concerning the place of delivery which was conceptualized using the three delays model.

In this study, the proportion of facility deliveries was $75.3 \%$. This proportion is quite higher than the proportion of $46.1 \%$ facility deliveries reported in the District annual review report (Ghana Health Service, 2017). However, the proportion is almost the same as the national facility delivery proportion (79\%) as found in a survey in Ghana (Ghana Statistical Service, Ghana Health Service \& ICF, 2018).

Most independent variables in the study were found to be predictors of health facility delivery. The variables that were employed in the multivariate logistic regression model were: maternal age, maternal education, travel time to the nearest facility, ANC attending, satisfaction of previous delivery place and preferred place for next delivery.

Maternal age in this study, like many other studies, was found to be associated with facility delivery. Younger women were more likely $(\mathrm{AOR}=10.21)$ to deliver in a health facility than their older counterparts. This seeks to explain that younger women might be more literate and more knowledgeable about the danger signs of pregnancy and the importance of delivering in a health facility. This is because younger women can adapt quickly to the growing trend of modernization and widespread social media networks. Hence, they have the ability to receive, interpret, and adopt health messages better than the aged.

Another reason could be that older women perceive home delivery as not risky as they have had previous safe home deliveries before. In other situations, younger women giving birth for the first time are at high risk, and providers would strongly recommend facility delivery. Furthermore, in typical villages of Northern Ghana, traditional beliefs still exist amongst older women than the younger ones. The older women have a strong belief that delivering in a health facility is not part of the ancestral customs.

This finding agrees with studies conducted in rural Northern Ghana (Boah et al., 2018), North Western Ethiopia (Tafere et al., 2018), and rural Kenya (Karanja et al., 2018). The Ethiopian study revealed that older pregnant women age $\geq 30$ years were more likely to give birth at home. Contrary to these findings, a study in rural India (Nair et al., 2012) reported that age has no impact on the decision to undergo health facility delivery. The different views from this study could be probably attributed to the population dynamics and the socio-cultural (the caste system) difference between India and other developing countries. 
With regards to maternal education, this study found that educational status among the respondents was low, with only $25.4 \%$ of them completing a junior high school while $38.1 \%$ had never attended school. Nonetheless, the educational level of the respondents was associated with health facility delivery (AOR=3.66). Respondents with higher educational backgrounds had a higher chance to deliver in a health facility. A possible reason could be that the more educated women are, the more knowledgeable they become about the dangers of pregnancy and would more likely give birth in a health facility. Also, educated women are more concerned about their health and have more autonomy. Hence, they have the ability and freedom to make decisions about their health, which eventually improves their health-seeking behavior. Another rationale could be that higher educated women are most likely to be employed. Therefore, they have money to attend and pay for health services. These results are consistent with studies from the Philippines (Shimazaki et al., 2013), Eastern-Ethiopia (Mehari, 2013), and Ghana (Sakeah et al., 2018).

Concerning the travel time taken by respondents to reach the nearest health facility, respondents have a fair chance $(\mathrm{AOR}=1.05)$ to give birth in a health facility if the time taken to reach the facility falls between 30-60 minutes. The effect of time to reach a health facility becomes stronger when combined with a lack of transportation and long-distance. Most rural dwellers are knowledgeable about the benefits of delivering their children at health facilities and are willing to do so, but poor road network, long-distance, and the long travel time to a health facility serve as great obstacles. A possible explanation could be that longer travel time is a disincentive to women, especially those with normal pregnancies. This is because longer travel times mean more transportation fares and more stress to reach the facility. Hence women prefer facilities closer to them than those far, even though the nearest facilities might not be able to provide all their health needs.

This finding confirms a study conducted in Nigeria, Ghana, and Sierra Leone; too far to walk, maternal mortality in context (Science et al., 2017). Contrary, a study in Tanzania concluded that travel time has a lower probability of delivering in a health facility (Kruk et al., 2009). The study justified this reason by stating that women preferred more-highly trained providers to travel on time to the facility. Like the Tanzanian study, another study in Kenya argued that distance from a health facility did not significantly predict the place of delivery since most facilities were within 5 kilometers walk (Kitui et al., 2013).

This study revealed that ANC coverage in the study area was $98.2 \%$ while women who made at least four ANC visits were $76.8 \%$. The figure is higher than the Ghana National ANC coverage rate of $81.3 \%$ (Ghana Health Service, 2015). 
In 2016, WHO recommended 8 ANC visits by pregnant women before delivery. This is an attempt to improve the quantity and quality of ANC for a positive pregnancy experience (WHO, 2016). Regardless of the benefits associated with this recommendation, it is challenging for poor women in subSahara Africa to comply with 8 ANC contacts with a health care provider before delivery. In poverty-endemic areas such as the WMM, most women prefer to work at farms and trade to be able to feed the family than having time for ANC visits. ANC attendance was a predictor of facility delivery, $\mathrm{AOR}=1.17$. The results show that the more health care provider receives women for ANC, the higher the chance of delivering in a health facility. The reason being that women detected with potential birth complications during ANC service are compelled to deliver in a health facility. More so, during ANC visits, women are counseled and encouraged to attend the next ANC sessions and this could subsequently lead them to deliver in a health facility. Additionally, preventive health educational services are given at ANC sessions to encourage women for safe delivery practices and this makes them likely to deliver in a facility. This result is in line with surveys conducted in Ethiopia (Tafere et al., 2018) and Burkina Faso (Allegri et al., 2015).

Women's opinion on satisfaction with their previous place of delivery was significant with health facility delivery $(\mathrm{AOR}=1.81)$. Regarding this, factors that could compromise and reduce clients' satisfaction include insufficient infrastructure, long waiting time, shortage of health workers, disrespect of health workers, inadequate essential drugs, and equipment. Women in deprived regions prefer to deliver at home than to pay for poor services at the health facility. The study findings confirm with studies in Eritrea (Araya et al., 2014; Kifle et al., 2018), and sub-Sahara Africa (Moyer \& Mustafa, 2013).

The preferred place for the next delivery was also positively associated with health facility delivery. Respondents who prefer to deliver their next pregnancy in a health facility were almost twice likely to deliver in a health facility than those who prefer to deliver at home. Possible reasons are that preferring to deliver the next baby in a health facility has a link with the quality of care received during the previous delivery. Women who received good quality delivery care service in their previous births in a health facility are more likely to deliver their next child in a health facility. Poor services rendered at health facilities such as lack of delivery equipment, inadequate health staff, and essential drugs may discourage women from delivering in health facilities. On the other hand, women who delivered previously at home, but experienced birth complications will be willing to deliver their next baby in a health facility. 
The results have similarities with studies in Nigeria (Okonofua et al., 2018), Northern-Zambia (Ensor et al., 2018), Britain (Laursen et al., 2009), and rural Southern Malawi (Kumbani et al.,2013).

The authors of this research wish to state that the findings of this study should be interpreted with caution. The different study environments, sample sizes, and methods might affect the accuracy of the results and might not be suitable for generalization in other areas.

\section{Strengths of the Study}

The study has a sizeable sample size and the results can be quite representative of the study population. Once more, quality control checks were put in place to minimize bias in the results. This included adequate training for research assistants before data collection and pretesting of the questionnaire. This provided an opportunity to identify and correct errors on the data collection tools before final data collection. The study moreover had adequate questionnaires to answer the research questions. Besides, the questionnaire contains a mixture of open and closed-ended questions that produced a variety of answers.

\section{Limitations of the Study}

There are some limitations in this study, and pragmatic steps were taken to minimize their effects. Firstly, there is the likelihood of recall bias since some of the respondents delivered more than a year before the study. Therefore, they might not be able to remember their birthing experiences. Also, the study was cross-sectional, so it could not define causality; it only described an association between the outcome and explanatory variables. Furthermore, the research assistants are natives of the study area and speak the same local language as the respondents, and this could influence the respondents' choice of answers. This problem was however minimized through effective training for the research assistants to be neutral as much as possible. More so, the study was quantitative and did not give room for respondents to express themselves very well on the topic. However, this issue was dealt with by adding a few open-ended questions to the questionnaire.

\section{Recommendations}

The following are recommendations for the policymaker's consideration:

1. The Government of Ghana should focus more attention on increasing access to regular ANC and delivery services at health posts. Regular outreach services should also be planned and carried out in remote areas. This will encourage women to deliver in health facilities.

2. Health care providers should draw a comprehensive birth preparedness plan with pregnant women before delivery. A properly designed and 
followed birth preparedness plan would subsequently lead women to deliver in facilities.

3. Male involvement in service delivery is vital, especially when rendering services to women in traditional settings. In typical traditional homes, the male has the strongest voice in decision making concerning seeking health care.

4. The Ministry of Health and the Ghana Health Service should reinforce the patients' chatter and the code of conduct and nursing ethics at all service delivery points. Changes in attitudes, behavior, and practices of health workers towards pregnant women would encourage facilitybased delivery.

5. Incentive support for women who deliver at health facilities would motivate others to deliver at the health posts. The Government should initiate an incentive package for women who deliver at health facilities.

6. Opportunities for female education with funding from the state and local Government could help expose women to valuable knowledge of health emergencies and provide them with functional decision-making autonomy for their health.

7. Intersectoral collaborations to address all associated factors preventing women from delivering in a health facility is recommended and would be beneficial for improving facility-based delivery in rural Northern Ghana.

\section{Conclusion}

In conclusion, this study sought to identify the predictors of health facility delivery in a rural district in Ghana. The finding shows that women's education, travel time to the health facility, decision-making autonomy, poor attitude of health workers, socioeconomic status, and unexpected delivery at home were the major factors influencing women's choice of delivery place. The study revealed a high ANC coverage (98.2\%), yet this did not translate into the proportion of facility deliveries. To bridge this gap, consented effort is needed for improvement in the health services provision, availability and accessibility of services, change in health workers' attitudes, and adequate education on the importance of facility delivery.

\section{References:}

1. Allegri, De., Ridde, V., Louis, V. R., Sarker, M., Tiendrebéogo, J., Yé, M., \& Jahn, A. (2015). Determinants of utilization of maternal care services after the reduction of user fees: A case study from rural Burkina Faso. Health Policy, 99(3), 210-218. https://doi.org/10.1016/j.healthpol.2010.10.010 
2. Araya, W., Johnson-Mallard, V., Evans, M. E., Beckstead, J. W., McNerney, D., Shelton, M. M., \& Jevitt, C. (2014). Overview of maternal mortality in Eritrea, sub-Saharan Africa. African Journal of Midwifery and Women's Health, 6(4), 171-175. https://doi.org/10.12968/ajmw.2012.6.4.171

3. Boah, M., Mahama, A. B., \& Ayamga, E. A. (2018). They receive antenatal care in health facilities, yet do not deliver there: Predictors of health facility delivery by women in rural Ghana. BMC Pregnancy and Childbirth, 18(1), 1-10. https://doi.org/10.1186/s12884-018-1749-6

4. Boerma, T. \& Mathers, C. D. (2015). The World Health Organization and global health estimates: Improving collaboration and capacity. BMC Medicine, 13(1), 1-4. https://doi.org/10.1186/s12916-015-02867

5. Cameron, L., Suarez, D. C., \& Cornwell, K. (2019). Understanding the determinants of maternal mortality: An observational study using the Indonesian Population Census. PLoS ONE, 14(6), 1-18. https://doi.org/10.1371/journal.pone.0217386

6. Campbell, O. M. \& Graham, W. J. (2006). Strategies for reducing maternal mortality: getting on with what works. Lancet, 368(9543), 1284-1299. https://doi.org/10.1016/S0140-6736(06)69381-1

7. Egharevba, MD., MPH, J., Pharr, J. R., Van Wyk, B., \& Ezeanolue, MD, MPH, E. E. (2017). Factors Influencing the Choice of Child Delivery Location among Women Attending Antenatal Care Services and Immunization Clinic in Southeastern Nigeria. International $\begin{array}{lllll}\text { Journal of } M C H & \text { and AIDS (IJMA), } & 6(1), & 82 .\end{array}$ https://doi.org/10.21106/ijma.213

8. Gabrysch, S. \& Campbell, O. M. R. (2009). Still too far to walk: Literature review of the determinants of delivery service use. $B M C$ Pregnancy and Childbirth, 9, 34. https://doi.org/10.1186/1471-23939-34

9. Gebrehiwot, T., San Sebastian, M., Edin, K., \& Goicolea, I. (2014). Health workers' perceptions of facilitators and barriers to institutional delivery in Tigray, Northern Ethiopia. BMC Pregnancy and Childbirth, 14(1). https://doi.org/10.1186/1471-2393-14-137

10. Ghana Health Service (2017). 2016 Annual Report. Accra. (June). Retrieved from http://ghanahealthservice.org/downloads/GHS_ANNUAL_REPORT _2016_n.pdf

11. Ghana Statistical Service (GSS), Ghana HealthService (GHS), \& ICF (2018). Ghana Maternal Health Survey 2017: Key Indicators Report. Accra, Ghana: GSS, GHS, and ICF.

12. GSS (2014). 2010 Population and Housing Census. Ghana Statistical 
Service, 1-117. https://doi.org/10.1371/journal.pone.0104053

13. J., K., S., L., \& G., D. (2013). Factors influencing place of delivery for women in Kenya: An analysis of the Kenya demographic and health survey, 2008/2009. BMC Pregnancy and Childbirth, 13, 1-10. Retrieved from http://www.biomedcentral.com/14712393/13/40\%5Cnhttp://ovidsp.ovid.com/ovidweb.cgi?T=JS\&PAGE= reference \&D=emed11\&NEWS=N\&AN=2013139710

14. Karanja, S., Gichuki, R., Igunza, P., Muhula, S., Ofware, P., Lesiamon, J., \& Ojakaa, D. (2018). Factors influencing deliveries at health facilities in a rural Maasai community in. 1-11. https://doi.org/10.1186/s12884-017-1632-x

15. Kifle, M. M., Kesete, H. F., Gaim, H. T., Angosom, G. S., \& Araya, M. B. (2018). Health facility or home delivery? Factors influencing the choice of delivery place among mothers living in rural communities of Eritrea. Journal of Health, Population, and Nutrition, 37(1), 22. https://doi.org/10.1186/s41043-018-0153-1

16. Kruk, M. E., Paczkowski, M., Mbaruku, G., De Pinho, H., \& Galea, S. (2009). Women's preferences for place of delivery in rural Tanzania: A population-based discrete choice experiment. American Journal of Public Health, 99(9), 1666-1672. https://doi.org/10.2105/AJPH.2008.146209

17. Kumbani, L., Bjune, G., Chirwa, E., Malata, A., \& Odland, J. Ø. (2013). Why some women fail to give birth at health facilities : a qualitative study of women's perceptions of perinatal care from rural Southern Malawi. 1-12. https://doi.org/10.1186/1742-4755-10-9

18. Laursen, M., Johansen, C., \& Hedegaard, M. (2009). Fear of childbirth and risk for birth complications in nulliparous women in the Danish National Birth Cohort. BJOG: An International Journal of Obstetrics and Gynaecology, 116(10), 1350-1355. https://doi.org/10.1111/j.1471-0528.2009.02250.x

19. Mehari, A. M. (2013). Levels and Determinants of Use of Institutional Delivery Care Services among Women of Childbearing Age in Ethiopia: Analysis of EDHS 2000 and 2005 Data [WP83]. DHS Working Papers, (38), 1-38.

20. Moyer, C. A. \& Mustafa, A. (2013). Drivers and deterrents of facility delivery in sub-Saharan Africa: a systematic review.

21. Nair, M., Ariana, P., \& Webster, P. (2012). What influences the decision to undergo institutional delivery by skilled birth attendants a cohort study in rural Andhra Pradesh, India. Rural and Remote Health, 12(4), 1-11.

22. Okonofua, F., Ntoimo, L., Ogungbangbe, J., Anjorin, S., Imongan, W., \& Yaya, S. (2018). Predictors of women' s utilization of primary 
health care for skilled pregnancy care in rural Nigeria. 1-15.

23. Press, D. (2017). Factors associated with institutional delivery service utilization in Ethiopia Factors associated with institutional delivery service utilization in Ethiopia. (September 2016), 463-475. https://doi.org/10.2147/IJWH.S109498

24. Rawe, K. (2011). Missing midwives.

25. Sakeah, E., Aborigo, R., Sakeah, J. K., Dalaba, M., Kanyomse, E., Azongo, D., \& Oduro, A. R. (2018). The role of community-based health services in influencing postnatal care visits in the Builsa and the West Mamprusi districts in rural Ghana. 1-9.

26. Science, S., August, M., Thaddeus, S., Maine, D., \& Maine, D. (2017). Too Far to Walk Maternal Mortality in Context TO WALK: IN. (November).

27. Shimazaki, A., Honda, S., Dulnuan, M. M., Chunanon, J. B., \& Matsuyama, A. (2013). Factors associated with facility-based delivery in Mayoyao, Ifugao Province, Philippines. Asia Pacific Family Medicine, 12(1), 1. https://doi.org/10.1186/1447-056X-12-5

28. Tafere, T. E., Afework, M. F., \& Yalew, A. W. (2018). Antenatal care service quality increases the odds of utilizing institutional delivery in Bahir Dar city administration, North Western Ethiopia: A prospective follow up study. PLoS ONE, 13(2), 1-14. https://doi.org/10.1371/journal.pone.0192428

29. UNICEF (2017). Annual Results Report Health. 1-110.

30. United Nations (2015). Millenium development goals. Retrieved from http://www.un.org/millenniumgoals/2015_MDG_Report/pdf/MDG 2015 rev (July 1).pdf

31. WHO, UNFPA, UNICEF, T. W. B. (1999). WHO | Reduction of maternal mortality. 44p. https://doi.org/978 9241561952

32. World Health Organization (2016). WHO recommendations on antenatal care for a positive pregnancy experience Executive summary. Maternal and Perinatal Health, (November). Retrieved from https://apps. who.int/iris/handle/10665/250800

33. Yaya, S., Bishwajit, G., Uthman, O. A., \& Amouzou, A. (2018). Why some women fail to give birth at health facilities : A comparative study between Ethiopia and Nigeria. 1-11. 